\title{
Fencing farm dams increases vegetation cover, water quality and macroinvertebrate biodiversity
}

\author{
Martin Westgate ${ }^{1}$, Mason Crane ${ }^{2}$, Ben C. Scheele ${ }^{3}$, Clare Crane ${ }^{3}$, Colleen O’Malley ${ }^{4}$, \\ Angelina Siegrist ${ }^{4}$, David Smith ${ }^{4}$, and David Lindenmayer ${ }^{1}$ \\ ${ }^{1}$ The Australian National University \\ ${ }^{2}$ Australian National University \\ ${ }^{3}$ Affiliation not available \\ ${ }^{4}$ Australian National University Fenner School of Environment and Society
}

February 22, 2021

\begin{abstract}
In many farming landscapes, aquatic features such as wetlands, creeks and dams provide water needed for stock and irrigation, while also acting as habitat for a range of plants and animals. Indeed, some species threatened by land use change may otherwise be considerably rarer - or even extinct - in the absence of these habitats. Therefore, a critical issue for the maintenance of biodiversity in agricultural landscapes is the extent to which the management of aquatic systems can help promote the integration of agricultural production and biodiversity conservation. We completed a snapshot cross-sectional study in southern New South Wales (south-eastern Australia) to quantify the efficacy of simple management practices - partial revegetation and stock reduction via fencing - for improving vegetation structure, water quality, and macroinvertebrate assemblages. We found that even short-term livestock exclusion resulted in increased vegetation cover. Relative to dams that were unfenced, those that had been partially or completely fenced for many years were characterized by reduced turbidity and nutrient levels and contained fewer thermotolerant (faecal) coliforms. They also supported increased richness and abundance of macroinvertebrates. In contrast, control (unfenced) dams tended to have high abundance of a few macroinvertebrate taxa. Notably, differences remained between the macroinvertebrate assemblages of fenced dams and nearby 'natural' waterbodies. Our results show how management interventions can improve water quality in farm dams and provide a valuable reference and baseline for longer term studies of farm dam improvement.
\end{abstract}

\section{Hosted file}

Westgate_etal_submissionVersion.pdf available at https://authorea.com/users/397157/articles/ 510147-fencing-farm-dams-increases-vegetation-cover-water-quality-and-macroinvertebratebiodiversity

\section{Hosted file}

Figure_1.pdf available at https://authorea.com/users/397157/articles/510147-fencing-farmdams-increases-vegetation-cover-water-quality-and-macroinvertebrate-biodiversity 


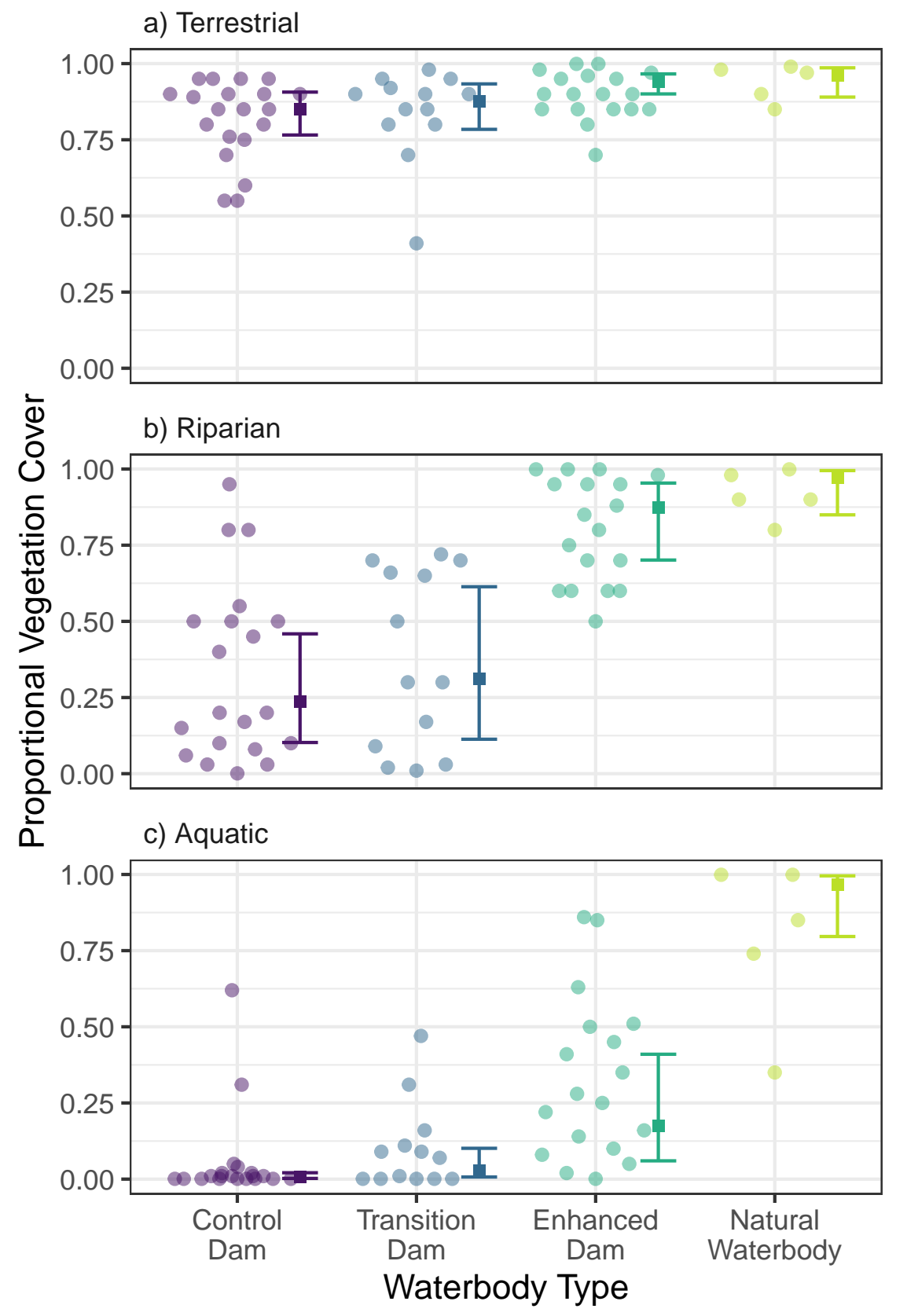



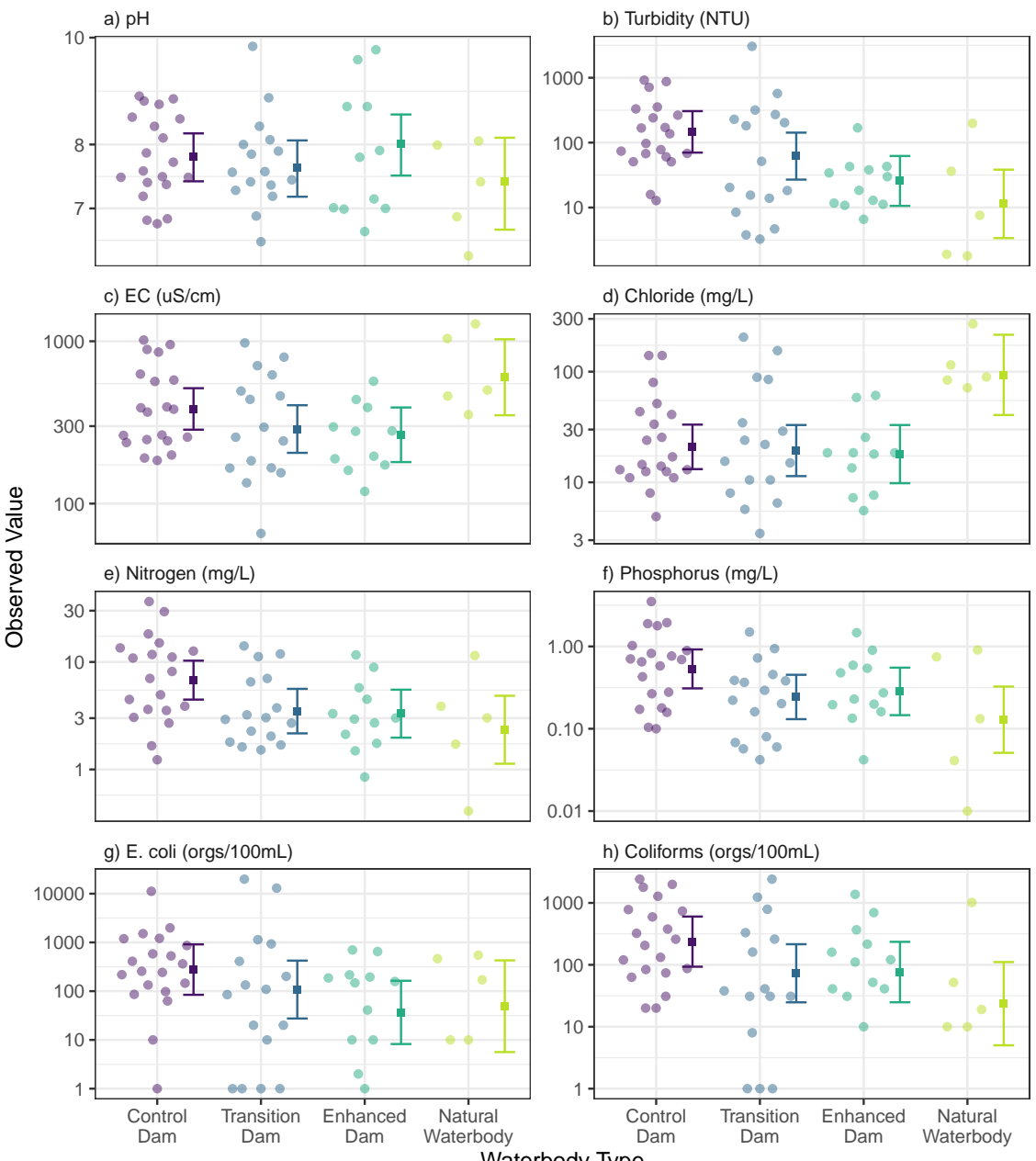

Waterbody Type 


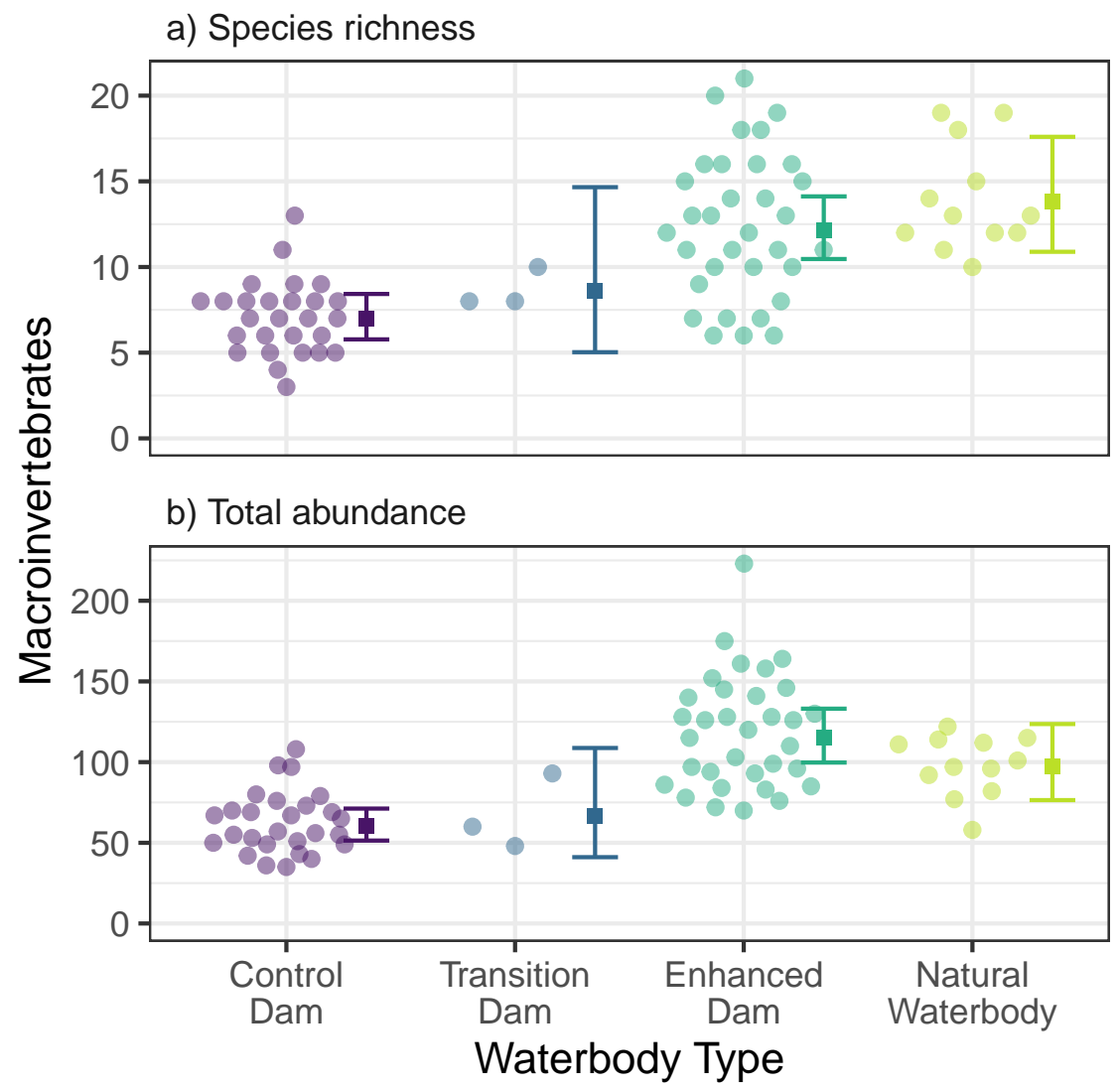


a) Enhanced Dams

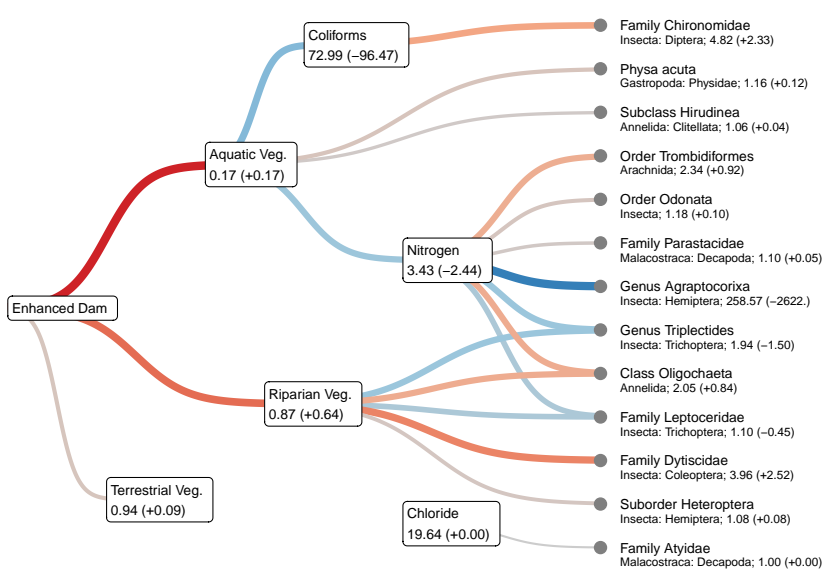

b) Natural Waterbodies

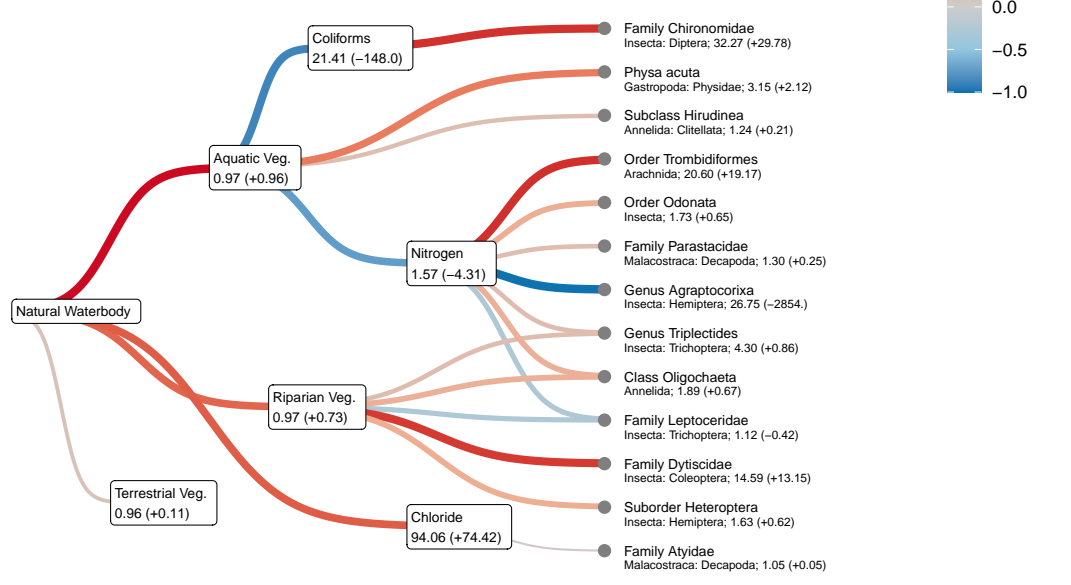

